\title{
The Role of Anchoring in Actualizing IT Affordances in EMR Implementations
}

\author{
Venkata Mallampalli \\ The University of Georgia \\ kmallampalli@uga.edu
}

\author{
Hani Safadi \\ The University of Georgia \\ hanisaf@uga.edu
}

\author{
Samer Faraj \\ McGill Univeristy \\ samer.faraj@mcgill.ca
}

\begin{abstract}
Affordances are useful theoretical tools to study IT mediated organizational change. Affordance actualization process provides a temporal structure to build a model that lays out a non-deterministic sequence to understand the changes that happen in organizations on the introduction of new IS. Affordances and affordance actualization have been studied in many contexts with the focus on material agency of the new IS or human agency of the user groups. Using the case of an EMR implementation in a family and urgent care clinic in Canada observed over 5 years, we discovered that anchoring on legacy systems in place before the EMR implementation has a significant influence in the actualization of affordances of the new IS. We present an affordance actualization process model including the anchoring influence observed, to provide a richer explanation of affordance actualization in EMR implementations.
\end{abstract}

\section{Introduction}

Defined as possibilities for goal oriented action offered by technical objects to specific user groups, affordances allow a holistic perspective on IT mediated organizational change [14]. As the theory of affordances was developed in ecological psychology [4], significant work has been done in IS research to define, conceptualize and apply the theory to IS specific phenomenon. The theory of affordances has been used to study the effects of information systems (IS) in multiple contexts including in healthcare [3, 17], social media $[12,19]$, and enterprise systems $[9,16]$. One aspect of the conceptualization has been the inquiry into the process of how affordances emerge, get actualized and lead to organizational change.

Affordance actualization is important because it provides a rich explanation of how IS affects work in organizations. Recent scholarship has theorized this process in various contexts [2, 3, 17]. In these studies, the organizational context is accounted for primarily by considering its influence on organizational goals. As affordances are defined as goal oriented action potentials, the link between organizational goals and individual goals provides an intuitive way to theorize the organizational context. On the other hand, new IS implementations in organizations must contend with existing organizational structures, such as organizational routines and legacy systems in the organizations. Thus, these aspects of the organizational context provide additional opportunity to contribute to affordance actualization theory.

In this study, we examine the role of preexisting legacy systems on affordance actualization process. Legacy systems are incumbent IS present in an organization and are in use by the users and groups prior to new IS implementation. Using the case of an electronic medical record (EMR) implementation in a family and urgent care clinic in Canada, we find that the affordance actualization of the EMR is heavily influenced by the incumbent hybrid system using paper records and other related information systems like electronic prescription systems and hospital patient administration systems. Though paper records were deprecated very early during the implementation of EMR, signaling a major break from the existing way of managing care, over the course of next five years, the hybrid system continued to play a role in shaping the perceptions and actions of the user groups involved. This influence of the legacy systems on the affordance actualization of the EMR system provides an enhanced explanation for the actions by user groups and ultimately the effects of EMR system implementation in that context.

\section{Literature Review}

IS affordances are defined as action potentials, i.e. what an individual or organization with a particular purpose can do with a technology or an information system [13]. While affordances require technical 
objects such as concrete or abstract functionality of IS, the action potentials still need to be actualized by human actors. Thus, affordances are a relational concept that accounts for both the materiality of technology and human agency to explain IT related effects. The concept has been used to study the effect of information systems in a variety of contexts e.g. social media [12, 19], health IT [3, 17], custom developed applications [9] and energy informatics [16].

Affordance actualization is the process through which "the actions taken by actors as they take advantage of one or more affordances through their use of the technology to achieve immediate concrete outcomes in support of organizational goals" [17]. The key factors influencing affordance actualization are material attributes (technical objectives), user and user group attributes, material and human actions and the organizational context of IS implementation. Various studies investigated the effects of these factors in different situations. For example, [19] theorize about connective affordances based on the property of user interdependence in the context of social media use. [9] find that the imbrication of user and material agency lead to gradual changes in affordances and organizational routines for a custom developed IT application. [16] focuses on the organizational context influencing energy efficiency practices enabled by the affordances of enterprise infrastructure. And [5] find that user agency plays an important role in health IT implementation and the actualization of the affordances of a computerized documentation system.

Further, affordance actualization is an unfolding process [20]. This process starts with perceiving the existence of affordances and proceeds with actualizing them and finally achieving some desired outcomes [2]. The emergence of affordances, especially their perception by the users has been called out as an area requiring further research [2]. However, the current knowledge and factors investigated, lean heavily toward the later part of the process, around the actualization and its organizational outcomes. Looking at the emergence of affordances requires considering potential additional factors present in many organizational IT implementation contexts. For example, when a new IS gets implemented, a major contextual factor influencing actualization of its affordances are organizational routines [5]. Past work practices affect affordances of new IS. The interaction between organizational routines and new technology leads to adaptations of both while the new technology is being routinized. Table 1 summarizes the papers, influential factors, and key findings.
Table 1: Literature review summary

\begin{tabular}{|c|c|c|}
\hline References & $\begin{array}{l}\text { Influencing } \\
\text { factors }\end{array}$ & Key Findings \\
\hline [14] & $\begin{array}{l}\text { Technical } \\
\text { Objects } \\
\text { User groups }\end{array}$ & $\begin{array}{l}\text { Functional } \\
\text { affordances are } \\
\text { defined as relations } \\
\text { between technical } \\
\text { objects and users. }\end{array}$ \\
\hline [9] & $\begin{array}{l}\text { User agency } \\
\text { Material } \\
\text { agency }\end{array}$ & $\begin{array}{l}\text { Change in } \\
\text { organizational } \\
\text { structure and routines } \\
\text { is caused by a } \\
\text { sequence of } \\
\text { imbrication that starts } \\
\text { from a perception of } \\
\text { affordances and } \\
\text { constraints }\end{array}$ \\
\hline [5] & User agency & $\begin{array}{l}\text { Agentic action guides } \\
\text { evolution of } \\
\text { affordances }\end{array}$ \\
\hline$[10]$ & User agency & $\begin{array}{l}\text { User workarounds for } \\
\text { constraints of } \\
\text { technology }\end{array}$ \\
\hline [16] & $\begin{array}{l}\text { Contextual } \\
\text { conditions }\end{array}$ & $\begin{array}{l}\text { Organizational goals } \\
\text { influence the } \\
\text { emergence of } \\
\text { affordances }\end{array}$ \\
\hline [17] & $\begin{array}{l}\text { Contextual } \\
\text { conditions }\end{array}$ & $\begin{array}{l}\text { Organizational } \\
\text { context influences the } \\
\text { individual } \\
\text { actualization of } \\
\text { affordances and } \\
\text { emergence of } \\
\text { organizational } \\
\text { affordances }\end{array}$ \\
\hline [3] & $\begin{array}{l}\text { Contextual } \\
\text { conditions }\end{array}$ & $\begin{array}{l}\text { Influence of effective } \\
\text { use on affordance } \\
\text { actualization }\end{array}$ \\
\hline
\end{tabular}

\section{A Theory of Affordances Actualization}

Affordance actualization is defined as the actions taken by actors as they take advantage of one or more affordances through their use of technology to achieve immediate concrete outcomes in support of organizational goals [17]. The first step in this process is the emergence of affordances [2]. The important factors at this step are derived from the definition of affordances as possibilities for goal oriented action offered by technical objects to specific user groups [14]. These factors are the properties of the technical objects and the user groups. IS properties are the features, interfaces, and 
representations within the new IS. Similarly, the goals of user groups are an integral part of the affordance emergence. Additionally, user properties like expertise have been suggested to influence affordance actualization. [2] suggest that expertise is related to the task that the user is expected to perform using the new IS [6]. While user's task expertise can be a factor for affordance actualization, expertise can also include user self-efficacy and expertise in activities related to IT usage, e.g. typing, or navigating graphical user interfaces.

The perception of affordances by user groups is suggested as the first step for affordance actualization [2]. Affordance perception has been argued to be different from affordance actualization, based on prior work suggesting that the information availability for perceiving them being a factor in affordances being salient to users [4]. In IS, this information is suggested to be in the form of symbolic expressions [14] and external information [2]. Because the perception of affordances is a cognitive process that requires recognizing the availability affordances and interpreting the symbolic expressions of the system, a deeper investigation of this part of the affordance actualization process requires attending to the cognitive aspects of system use by user groups. Finally, after being perceived, the actualization of affordances depends on the level of effort required to actualize them [2]. Effort influences affordance actualization by triggering cognitive processing by users on the benefits of actualizing an affordance. Table 2 defines the relevant constructs of the affordance actualization process.

\subsection{Anchoring and Affordances Actualization}

Affordance actualization requires actions by user groups to eventually lead to concrete outcomes. As such, these actions require cognitive effort till the use of new IS is routinized. The affordance actualization process captures the cognitive actions involved from perceiving affordances to their actualization and achievement of the concrete outcomes that the actors desire. However, a cognitive process is a subject of various biases. When a new IS gets implemented in an organization, key actors may have cognitive biases based on their expertise, self-efficacy, experience, work practices and organizational routines. One bias with potential impacts is anchoring bias, defined as the tendency of decision makers to be biased towards an initially presented information [18].

Anchoring has been looked at in IS in the form of status quo bias when a new IS gets implemented [7, 15]. Users of IS also develop habits which influence how they perceive and adopt new IS [11]. However, while habit and switching cost explain the adoption of the new system, they do not explain how it will be used once adopted. We posit that in addition to influencing adoption and initial use, anchoring influences the actualization of new affordances once a new IS gets adopted and used. First, existing organizational routines are a potential source of initial information present with the actors. Actors therefore anchor on existing organizational routines while developing new routines around the new IS [5]. Second, another potential source of information for anchoring is an existing technical artifact, a legacy system that is already in use prior to the new system implementation.

When a legacy system is present in the organization, users can be expected to have a significant level of expertise with achieving their goals using it. As a result, users have already actualized its affordances. So, the legacy system provides a salient point of comparison when a new system is implemented. The main mechanism of this influence is when users compare the affordances of the legacy system and what they perceive to be the affordances of the new system. This comparison can be favorable or unfavorable to the new system, i.e. users could perceive that the new system is more efficient or effective in achieving their goals or it could be more constraining. With a favorable comparison, it is likely that there is enthusiastic acceptance for a new system. There is a possibility of resistance in case of an unfavorable comparison.

In addition to anchoring on legacy system affordances, there is also a possibility that users perceive existence of affordances in the new system which are like the old system but require actualization effort. This discrepancy potentially leads to resistance from the users [8]. In summary, the presence of a legacy system can be a powerful influence on the perceptions of the users and lead to the perception or misperception of affordances of the new system. Therefore, it is likely that actors making decisions in the affordance actualization process anchor on this information, influencing their actions. The goal of this study is to examine how anchoring on a legacy system affect the actualization of affordances when a new IS is implemented.

Table 2: Affordance Actualization Constructs

\begin{tabular}{|l|l|c|}
\hline Construct & Description & References \\
\hline Technical & Material & {$[14]$} \\
Object & $\begin{array}{l}\text { properties with } \\
\text { causal potential. }\end{array}$ & \\
& $\begin{array}{l}\text { This refers to } \\
\text { properties of both } \\
\end{array}$ & \\
& the legacy system & \\
\hline
\end{tabular}




\begin{tabular}{|c|c|c|}
\hline & $\begin{array}{l}\text { and the new } \\
\text { system. }\end{array}$ & \\
\hline User Goals & $\begin{array}{l}\text { The end outcomes } \\
\text { that users want to } \\
\text { achieve by using } \\
\text { the features of an } \\
\text { IT system }\end{array}$ & [14] \\
\hline $\begin{array}{l}\text { User Task } \\
\text { Expertise }\end{array}$ & $\begin{array}{l}\text { Competency, } \\
\text { experience, and } \\
\text { training on the } \\
\text { tasks performed } \\
\text { by users as a part } \\
\text { of their job } \\
\text { description }\end{array}$ & [6] \\
\hline $\begin{array}{l}\text { Information } \\
\text { about } \\
\text { affordances }\end{array}$ & $\begin{array}{l}\text { Information about } \\
\text { new system } \\
\text { affordances from } \\
\text { symbolic } \\
\text { expressions and } \\
\text { other sources }\end{array}$ & {$[2,14]$} \\
\hline $\begin{array}{l}\text { Actualization } \\
\text { effort }\end{array}$ & $\begin{array}{l}\text { The degree of } \\
\text { difficulty in } \\
\text { actualizing an } \\
\text { affordance }\end{array}$ & {$[2]$} \\
\hline $\begin{array}{l}\text { User Legacy } \\
\text { System } \\
\text { Expertise }\end{array}$ & $\begin{array}{l}\text { Users' } \\
\text { competency, } \\
\text { experience, and } \\
\text { training with the } \\
\text { legacy system } \\
\text { currently in use }\end{array}$ & $\begin{array}{c}\text { New } \\
\text { Construct }\end{array}$ \\
\hline $\begin{array}{l}\text { Legacy } \\
\text { actualized } \\
\text { affordances }\end{array}$ & $\begin{array}{l}\text { The actualized } \\
\text { affordances of } \\
\text { legacy system } \\
\text { currently in use. }\end{array}$ & $\begin{array}{c}\text { New } \\
\text { Construct }\end{array}$ \\
\hline
\end{tabular}

\section{EMR implementation case study}

The context of this study involves the implementation of an open source EMR system in a medium sized clinic in Canada. The clinic provides two clinical services: a walk-in clinic provides outpatient care services without requiring prior appointment, and a family medicine clinic provides a longer-term patient following care with typically the same physician associated with a patient over their medical history. The clinic is affiliated with a university hospital health system receiving and sending patients from other facilities within the system. The clinic is owned and managed by senior physicians who both manage the clinic and provide care to patients. The clinic serves about 30,000 patients a year with a staff of 38 physicians, 15 nurses and 10 administrative personnel.

Prior to 2008, the clinic was operating using a hybrid system, with paper based charts and piecemeal electronic systems. Paper documents were exchanged using couriers with other facilities in the hospital network to ensure sync-up of information. With increased utilization of its services, physical constraints for the storage of paper records increased the urgency for a solution to the problem of lack of space to maintain paper records. Electronic medical records were thought to be a solution, but the clinic was constrained by the funding requirements for proprietary systems. The alternative to use an open source EMR system was considered feasible by one of the managing physicians based on an assessment of its basic functionality being competitive enough to more sophisticated proprietary solutions. While the open source system was already being extensively used in British Columbia, this would be the first implementation of this system in the province where the clinic is based.

Furthermore, the physicians of this clinic were compensated directly by the single payer system in Canada on a patient consultation basis. Thus, the adoption of EMR by individual physicians was considered voluntary and physicians could choose whether to use or not use the system. The lower cost of the open source system was a significant factor in allowing its voluntary use, as the clinic management was not under pressure to ensure return on investment on the system by forcing adoption. This also minimized the risk of alienating physicians who under the direct compensation system could choose to withdraw from serving in the clinic. The open source nature of the system was also advertised as a strength by allowing customization to the needs of the clinic.

The key stakeholders for system were the physicians, nurses, administrative staff, and the clinic managers. Due to the size of the clinic, the system implementation happened quickly and all major components were in operation within a space of 2 months in 2008. Over the course of next 5 years, interesting changes were observed by one of the authors who was involved in studying the EMR implementation in an exploratory manner from the beginning. Data was collected through intensive interviews with the key user groups. Initial data analysis focused on the attitudes of the user groups to the EMR system. Through inductive theory building, the process of affordance actualization was found to be useful to understand the changes observed and further data analysis. Subsequent data analysis and theorizing focused on affordances actualized, and outcomes achieved. 


\subsection{Initial adoption phase (2008)}

At the outset, the implementation was championed by one of the managing doctors, who had prior experience with EMR systems in the UK. As the clinic was part of a hospital system with many patients using multiple affiliated facilities at different sites, there was considerable effort being spent coordinating care using paper across the system. So, a lot of the expectations of all user groups around the EMR system was to alleviate this effort and costs of maintaining the paper based coordination. E.g. it was believed that the effort for follow up phone calls to receive the required information would be reduced. Moreover, it was thought that the delays involved in the movement of papers across facilities will be reduced and instantaneous access to required information will be available. Especially for the administrators, reduction in coordination effort was a reason for enthusiastic adoption of the EMR system.

Well, since we are like three or four clinics together, we are all going to share the files. So it's good because one doctor can see special notes in different clinics, so that's great. I won't have to fax or send all the results to different clinics. So that's one great thing. And we'll have, hopefully, all the results online, also. So I don't have to call, you know, different clinics - also hospitals - to get the results. We can just look on OSCAR and have them there. So yeah, it's good. (Admin NS)

The administrators' user group perceived the affordance of Accessing and using patient information anytime and anywhere [17]. The physicians' user group was focused more on the effect on patient care outcomes while perceiving the affordance of Accessing and using patient information anytime and anywhere.

Well, first of all, for me as a doctor, finding out what happened to my patient the night before, I'll have immediate access to the file. And if I'm working at the walk-in clinic myself wondering what medication my patient is on, and what their past medical history is, it would be immediately accessible to me. So, I'll be able to do a better job in delivering healthcare to the patient, and the patient benefits from that. (Managing Physician RM).

At this stage of EMR implementation, different user groups were perceiving some common affordances of the system. However, they were also comparing the EMR system workflow with the paper record workflow to assess the affordances of the EMR system available to them.

I find it very cluttered. Yep. Like the screen is not reading-friendly. It doesn't open like a chart, like it should be. But I guess it's getting used to it. But there's so much stuff on the top. And the actual notes - that's what I want to read. I want to know what are the notes from the last visit. It is in the centre, but it's kind of small ... I couldn't draw on it. There were no pictures, and I think sometimes, you know, saying "there's a one by three-centimeter lump in the breast" it's easier for me to draw the breast and show it exactly where it is, because... and it's easier for everyone to look at that picture, rather than my measuring it saying "it's in the right upper-lateral quadrant." (Physician TC)

Thus, during the initial stages of the implementation, there were both common perceived affordances across user groups, along with role specific evaluations of the EMR features. Subsequently, the role specific evaluations would lead to different user groups to make differential uses of the features of the system to recover different affordances based on the immediate outcomes desired by them.

\subsection{Significant adoption stage (2010)}

Two years into the implementation the EMR system is being used by most the personnel in the clinic. However, the change in workflow due to the implementation of EMR is bringing new issues to the foreground, especially those related to the availability of data in the system. In the paper based system, a process had been set up to make the paper charts available to doctors based on the patients that they were scheduled to see.

We get all our charts from the hospitals, which is the [hospital 1] and the [hospital 2], which is sent here 3 times a day. And we go by the appointments. We order by appointments or if there is an insurance form we order all the charts from the hospital. So, it's morning $8 o^{\prime}$ clock, 12, and if we need another one at 2, but usually it's at 4 at the end ... They [the charts] are prepared in the mornings, the day before sorry, and then placed in their rooms. (Admin JN)

The paper medical record afforded information consolidation to the personnel of the clinic and they could use the paper record to coordinate care. However, this process would make charts available only for prior appointments. In the case of walk-in patients, the doctors did not have the patient charts available to them. With the implementation of EMR, it was expected that the patient charts would be available across all the sites of the care network without requiring any coordination effort and physical movement of paper. However, the lead hospital of this network was implementing its own patient administration system and digitizing the paper charts that it held. 
Definitely, there's walk ins all the time. Most of the time it's for one particular thing, otherwise they could come in and the doctors will see them either way. And in that case, there's no charts ... Everything, and patient charts is coming in there. Right now, they are scanning and putting everything into [hospital EMR] right now. Charts, it will be this chart, right now there are bloods, anything transcribed, cardiology and discharge summaries, emergency, it's all there. Patient demographics and appointments. (Admin JN)

Due to a lack of integration between the clinic's EMR and the hospital system, the seamless exchange of data was not actualized. Where the availability of patient data was not critical for delivery of care, e.g. walk-in patients, the clinic EMR was being used. In the case of family clinic, the doctors were having significant difficulty in recovering the affordance of information consolidation that was available with the paper record.

Here you are having a patient. And they're definitely a population is 70 and over, and there is a very small population of about $20 \%$ that are under. So, you have diabetes, hypertension, the whole gamut. I think this is what their biggest problem is, the prescriptions, 2 page prescriptions that have to be entered in, yes the nurses can do it, that's fine. But you have a clinic with 25 patients all of them with these huge dossiers, you know, 4 volumes. It gets a little overwhelming. That's what I was telling you about the doctor that started and stopped, because she just got overwhelmed. She was spending more time trying to find and get accustomed to it, which she finally did, it was just the information was too much to put in. (Admin JN)

The lack of information consolidation limits the potential benefits to quality of care that could be derived from the EMR system. Similarly, the process of coordinating the availability of lab results also requires effort from the administrators to make them available in the EMR system. This requires additional steps for both making the data available and its use by the doctors in the care process.

I could see potential benefits where we would have access to medical information from other sources on the computer. For example, from hospitals, records from other sources. But so far, I haven't found any real difference. (Physician ME)

The faxes are coming in and being dropped into a folder on the desktop which is been viewed by the nurse. All the normal results are being sent into the patient [EMR] folder and a message is being linked from that folder, from the patient's demographic to the doctor telling him that the lab results are coming and that they are normal. All the abnormal results are still being viewed on paper format because they need to be signed by the treating doctor or the doctor who sent the patient into the lab. So the abnormal results are still being printed the patient is being called back for a follow up by the nurse and then the doctor will sign the results once, well not once the patient is in, but as soon as the nurse calls (Admin $P C)$

The paper record also afforded free form input of data through writing on the relevant documents included in the patient chart. The structure of data in the EMR system did not allow free form input anymore. So, physicians engaged in actions to recover this affordance when using the EMR system.

I just saw a patient for example in the walk-in clinic. I am reviewing lab results and I put them in. It just takes too much time, why you want your patient to come back is not because, the real reason you want them back is because you look at the lab result and unless you know why you ordered the test, you don't know whether it is a normal follow up, a normal result or the abnormal result that is significant. When, previously, I would have taken their result, had a paper chart, and I would have written a note on the actual lab result why I was following up or what to do. (Physician WJ)

At this stage of the implementation, the affordance of accessing and using patient information anytime and anywhere has been actualized and various user groups are able to perform order and perform their tasks in ways more suited to them. The physicians can look at patient data outside of the clinic and communicate with nurses or administrators for follow up activities in advance. However, the affordance of information consolidation is not actualized due to the lack of connectivity with other sites within the hospital network. This affordance was available with the earlier paper record system through physical transfer of records between different sites. To recover this affordance while using EMR, different user groups are required to engage in various actions to make up for the lack of information consolidation with the EMR system.

\subsection{Mature adoption stage (2012)}

At four years from the implementation of the EMR system, more affordances of the EMR system have been actualized. For example, administrators, nurses and physicians are now able to perform artifact centric coordination [1]. This is done using the tickler and messaging features available in the EMR system. The messaging and tickler features allow both general communication between the user 
groups, and communication linked to specific patient records.

I'm going to send a tickler to the doctor. Let's say that the doctor sees you today - so next year someday he can bill an extra fee. so, I'm going to, for [clinic EMR], tack all his patients so in a year when you come back, I'll know. Because it's impossible to follow 500 patients like that. Yes, and you can bill that code twice, but once per year. So I'm getting to use the tickler for the first time. Tracking issues (Admin SN)

Artifact centric coordination also results in less effort for different user groups as the availability of the artifact in the form of the electronic record, allows them to coordinate more easily compared to paper records. In addition, accessing and using patient information anytime and anywhere is utilized heavily by physicians, which they could not do with the paper records.

Well the form of communication with the patients? Well doctors check the results, and if there were a problem with them they would give it to the nurses around there and even then, sometimes they would put it in a box so there's still no communication. Just what is written on the paper. This is much better because at least you have the patients chart and you can follow back in. (Nurse TA)

I think paper charts I have probably tried to stay a little more on top of it, but electronically because I can take it home too, I can do it from home, so if I'm, if it's the end of the day and I just want to get through my patients so I can get out of the clinic, I know that I can do it at home and don't have to bring charts with me. So as long as I get the basics down, save it, see my next patient quickly, and then do it at home. (Physician BM)

Patients could also be accommodated by the administrators depending on physicians' availability and patient data would be available to the alternate physician. However, the continued lack of information consolidation requires users of the EMR to perform additional tasks to be able to recover the affordance. While the information from the lead hospital in the network is available in an electronic system, it is not integrated with the EMR at the clinic. So, physicians must keep both systems open side by side to be able to refer to the information they require.

A patient can have something urgent today, and call me up and say, "I need to see my doctor today", and that's great. And they come. But there are going to be days where the doctor is full here. And we are not able to place you with another doctor. They can go to the walk-in clinic and the doctor who sees them there can see, access their file. (Admin $S$ )
Yeah, it's too bad we could not incorporate an EMR into <hospital system> directly, which would be a good thing. That way we have labs, radiology, visits and scheduling, everything on one database, one username and password... that would be a good thing. Because it seems <clinic EMR> is going all over the place, but $<$ clinic EMR $>$... you know. It's got its advantages - I can see a patient in walk-in and two weeks later follow-up on $<$ clinic EMR $>$ right from my office, which is a good thing. But it would be nice to have it more unified, and work much better in all the different applications and interfaces. (Physician SN)

In some cases, the administrators must scan in the paper results received from different sources to ensure that patient data is available in an electronic form. However, the scanned results were put into the EMR system only as image attachments, which do not serve the purpose of creating a proper record of the data needed to be present in an EMR. This process was alluded to by the administrators right at the beginning in initial adoption phase, and this was still prevalent, 5 years into the implementation.

No, we scan them and then we shred them once they are in the computer. That's it. They get scanned into the computer and the doctors can access it. And then we just discard them (Admin JA)

At this point, the EMR system affordances of access to information and artifact centric coordination have been actualized. However, the affordances available with the legacy system, free form input of data and information consolidation were still not actualized with the EMR system, requiring user groups to engage in additional activities to recover those affordances. In the case of information consolidation, one such activity being performed by the physicians is that they have two systems open side by side, referring to the information within the system that better represents their need. With the legacy system, all the information present at the lead hospital was physically made available at the clinic during the consultation. Thus, information consolidation was a key affordance available with the legacy system.

With an EMR implemented at the clinic, it was expected that it could seamlessly connect to the lead hospital's system and information consolidation would be available and in fact be more effective due to faster availability of data to the clinic. However, in practice, the integration between the systems did not happen and the physicians and administrators had to engage in different actions for continued access to the information they had earlier. Physicians kept two systems open side by side, requested additional paper records of data that was available in electronic form, 
and administrators scanned in paper documents that were still being received from different sources. Though this resulted in the clinic EMR having the required data in electronic format, it was neither efficient nor effective in helping the physicians during their care delivery process.

\section{Discussion}

EMR implementation has been studied previously from an affordance actualization perspective [17]. In our study, we observe affordances that have been theorized in the prior literature such as accessing information anytime and anywhere, and artifact centric coordination[1, 17]. Because the EMR is an important shared data repository, all participants in care provision find it easy to refer to the information present in the record to the extent of even coordinating with each other around the shared patient level EMR artifact available in the system. While features like messaging and ticklers were used for general communication and coordination between different user groups, they were also used specifically to coordinate with the EMR artifact. This suggests that coordination using EMR happens both on general tasks as well as very specific patient care related tasks centered around the artifact. Table 3 provides details of the affordances of EMR that were identified in our data.

Table 3: Actualized affordances of EMR

\begin{tabular}{|c|c|}
\hline \multicolumn{2}{|c|}{ Accessing information anytime and anywhere } \\
\hline $\begin{array}{l}\text { Technical } \\
\text { Object }\end{array}$ & Electronic Data Storage \\
\hline Physician & $\begin{array}{l}\text { Availability of patient information } \\
\text { beyond clinic setting and times. } \\
\text { Affords better patient following and } \\
\text { quality of care due to patient } \\
\text { information available at the doctor's } \\
\text { convenience. Affords better } \\
\text { coordination with admins and nurses. }\end{array}$ \\
\hline Nurse & $\begin{array}{l}\text { Shared affordance with doctors, } \\
\text { which allows better quality of care }\end{array}$ \\
\hline Admin & $\begin{array}{l}\text { Shared affordance with doctors, } \\
\text { which allows better quality of care }\end{array}$ \\
\hline \multicolumn{2}{|r|}{ Artifact centric coordination } \\
\hline $\begin{array}{l}\text { Technical } \\
\text { Objects }\end{array}$ & $\begin{array}{l}\text { Electronic Data Storage; Messages } \\
\text { and Ticklers }\end{array}$ \\
\hline Physician & $\begin{array}{l}\text { Coordinate patient care workflow } \\
\text { through data and features of the } \\
\text { EMR system. Affords shared } \\
\text { representation of data and } \\
\text { possibilities of workflow }\end{array}$ \\
\hline
\end{tabular}

\begin{tabular}{|c|l|}
\hline \multirow{5}{*}{ Nurse } & $\begin{array}{l}\text { coordination through the system with } \\
\text { other user groups } \\
\text { Coordinate patient care workflow } \\
\text { through data and features of the } \\
\text { EMR system. Affords shared } \\
\text { representation of data and } \\
\text { possibilities of workflow } \\
\text { coordination through the system with } \\
\text { other user groups }\end{array}$ \\
\hline Admin & $\begin{array}{l}\text { Coordinate patient care workflow } \\
\text { through data and features of the } \\
\text { EMR system. Affords shared } \\
\text { representation of data and } \\
\text { possibilities of workflow } \\
\text { coordination through the system with } \\
\text { other user groups }\end{array}$ \\
\hline
\end{tabular}

Moreover, the actualization of the EMR system's affordances were observed as an evolution over time, thus providing support for the existence of affordance actualization process. Therefore, our case supports and strengthens the findings of previous literature. We also observe that the EMR system's features and affordances were constantly compared by the user groups to the legacy system that existed before the implementation (e.g. the paper chart and other health IT systems). Table 4 below documents two affordances of the legacy system that were identified from our data. These affordances were fully actualized as the systems were in existence for a long period of time before the EMR implementation. For example, information consolidation with the legacy system was actualized through physical movement of records between the sites of the hospital system and the availability of specific information like lab reports in the hospital patient administration system.

Table 4: Actualized affordances of legacy system

\begin{tabular}{|c|l|}
\hline $\begin{array}{c}\text { Technical } \\
\text { Object }\end{array}$ & $\begin{array}{l}\text { Patient Chart } \\
\text { Pecord patient medical history in a } \\
\text { single record. Affords following } \\
\text { patient over long medical histories and } \\
\text { reference to previous issues and } \\
\text { treatments. }\end{array}$ \\
\hline Nurse & $\begin{array}{l}\text { Record preliminary information and } \\
\text { provide initial care. Affords creation } \\
\text { of information that is potentially } \\
\text { useful for further diagnoses and } \\
\text { investigation by doctors }\end{array}$ \\
\hline Admin & $\begin{array}{l}\text { Record all information about patient } \\
\text { visit history along with medical } \\
\text { information. Affords administrators } \\
\text { access to previous visit history and }\end{array}$ \\
\hline
\end{tabular}




\begin{tabular}{|c|l|}
\hline & perform patient following as required \\
\hline $\begin{array}{c}|c| \\
\text { Technical } \\
\text { Object }\end{array}$ & Patient Chart \\
\hline \multirow{5}{*}{ Physician } & $\begin{array}{l}\text { Record information in a form which } \\
\text { allows efficient representation of } \\
\text { diagnostic information. Affords } \\
\text { entering unstructured information as }\end{array}$ \\
$\begin{array}{l}\text { required to create a better } \\
\text { representation of the medical } \\
\text { condition. E.g. using spatial } \\
\text { representation like marking on image } \\
\text { of a human figure to display locations }\end{array}$ \\
\hline
\end{tabular}

It was expected that information consolidation would be more efficient and effective with the implementation of the EMR system. However, during the period of observation of the implementation, various organizational and regulatory challenges prevented connection of the electronic systems between the sites. Therefore, an affordance that was available with the legacy system was no longer effectively available with EMR. As this affordance was fully actualized with the legacy system, it provided a salient comparison with the affordances of the EMR system, highlighting its deficiency and the potential effort required to perform some actions with the new system, that were very easy with the legacy system.

As the legacy system was deprecated, different user groups engaged in various activities to partially recover this affordance while using the EMR system. For example, physicians either requested additional paper records of lab results and patient charts or used the lead hospital's patient administration system along with the clinic's EMR system to achieve information consolidation. The lack of information consolidation prevented the actualization of several other affordances that were identified in previous literature such as standardizing data, processes, and roles and incorporating rich information into clinical decision making. Similarly, the unavailability of free form input of data in the EMR system, resulted in user groups expressing dissatisfaction with the usability of the EMR system. Eventually, users performed specific actions to partially recover this affordance through the EMR. This demonstrates the value that user groups placed on this affordance, e.g. recording information in specific fields of the EMR.

These two actualized affordances of the legacy system shaped the perceptions and actions of the user groups as they were not approaching EMR as a purely a technical object that could be used to achieve their goals, but as a system that had advantages or disadvantages compared to the legacy system. The easiest comparison that they could perform was not specific features of the systems but between what was afforded by the legacy system versus the EMR. Therefore, analyzing affordances of the EMR system alone is inadequate unless the context of the system implementation is brought to the foreground. As new information systems are often implemented into organizations that have existing legacy systems and organizational routines, attending to these contextual features is important in providing explanations of IT mediated organizational change using the affordance theoretical lens.

Furthermore, we observe that users compared the actualized affordances of the legacy system and the affordances of the EMR and subsequently, engaged in actions intended to recover the actualized affordances of the legacy system. This was done despite the additional effort involved such that, legacy affordance recovery becomes a goal for the users. The user groups engaged in affordance recovery actions to actualize the same perceived affordances as with the legacy system.

The influence of the legacy systems operates through different mechanisms based on the properties of technologies, user characteristics and perceptions. Prior actualized affordances of a legacy system influence the perception of a new system's affordances by providing a salient comparison for

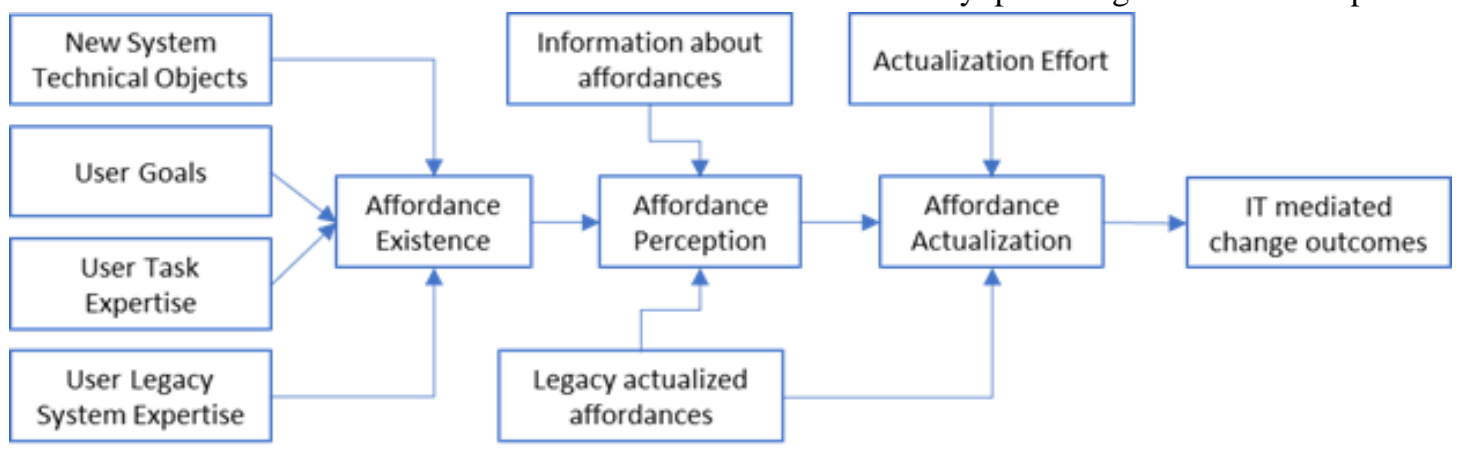

Figure 1: Affordance Actualization Process Model 
user groups. They also influence affordance actualization when user groups engage in affordance recovery actions where they perceive being able to recreate legacy system affordances with the new system. Therefore, considering the influence of legacy systems provides a potentially richer nondeterministic explanation of IT mediated change outcomes observed in different contexts and situations. We propose to extend the actualization process model by [2] to our findings on the legacy system constructs and their potential influence at various stages of the process (Figure 1).

\section{Conclusion}

Affordances are a useful theoretical concept for studying IT mediated organizational change. Affordances have been used to study a wide variety of contexts. Affordance actualization provides a rich process based structure to study the temporal evolution of affordances over time from the initial perception to the organizational effects. In organizational contexts, new IS implementations usually must contend with existing structures like organizational routines and legacy information systems. Incorporating these important features of organizational context requires us to study their influence on affordance actualization.

Using an inductive approach for studying an EMR implementation in a clinic in Canada, we found significant influence of the legacy information system in place before the implementation on how the EMR was adopted and routinized. By including the constructs related to legacy information systems in affordance actualization process, we can explain the effects of the EMR implementation, we observed in our case. Considering the legacy system's influence provides a useful method to incorporate the information that user groups make use of when they perceive and actualize affordances of the new system.

\section{References}

[1] Arazy, O., Daxenberger, J., Lifshitz-Assaf, H., Nov, O., and Gurevych, I. "Turbulent stability of emergent roles: The dualistic nature of self-organizing knowledge coproduction." , Information Systems Research, 27(4), 2016, pp. 792-812.

[2] Bernhard, E., Recker, J.C., and Burton-Jones, A. "Understanding the Actualization of Affordances: A study in the process modeling context." , International Conference on Information Systems, (2013).

[3] Burton-jones, A. and Volkoff, O. "How can we develop contextualized theories of effective use? A demonstration in the context of community-care electronic health records.", Information Systems Research, (Forthcoming), 2017.

[4] Gibson, J.J. "The Theory of Affordances." In The Ecological Approach to Visual Perception. Houghton Mifflin Company, Boston, MA, 1979.

[5] Goh, J.M., Gao, G.G., and Agarwal, R. "Evolving Work Routines: Adaptive Routinization of Information Technology in Healthcare Evolving Work Routines." , Information Systems Research, 22(3), 2011, pp. 565-585.

[6] Goodhue, D.L. "Understanding User Evaluations of Information Systems." , Management Science, 41(12), 1995, pp. 1827-1844.

[7] Kim, H.-W. and Kankanhalli, A. "Investigating User Resistance to Information Systems Implementation: A Status Quo Bias Perspective.”, MIS Quarterly, 33(3), 2009, pp. 567-582.

[8] Lapointe, L. and Rivard, S. "A Multilevel Model of Resistance to Information Technology." , MIS Quarterly, 29(3), 2011, pp. 461-491.

[9] Leonardi, P.M. "When Flexible Routines Meet Flexible Technologies: Affordance, Constraint, and The Imbrication of Human and Material Agencies.”, MIS Quarterly, 35(1), 2011, pp. 147-167.

[10] Leonardi, P.M. and Barley, S.R. "What's Under Construction Here? Social Action, Materiality, and Power in Constructivist Studies of Technology and Organizing.", The Academy of Management Annals, 4(1), 2010, pp. 151.

[11] Limayem, M., Hirt, S.G., Cheung, C.M.K., and Hirt, S.G. "How Habit Limits the Predictive Power of Intention: The Case of Information Systems Continuance." , MIS Quarterly, 31(4), 2007, pp. 705-737.

[12] Majchrzak, A., Faraj, S., Kane, G.C., and Azad, B. "The contradictory influence of social media affordances on online communal knowledge sharing." , Journal of Computer-Mediated Communication, 19(1), 2013, pp. 3855.

[13] Majchrzak, A. and Markus, M.L. "Technology Affordances and Constraints in Management Information Systems (MIS)." In Encyclopedia of Management Theory. Sage Publications, 2012, 5.

[14] Markus, M.L. and Silver, M.S. "A Foundation for the Study of IT Effects: A New Look at DeSanctis and Poole's Concepts of Structural Features and Spirit." , Journal of the Association for Information Systems, 9(10), 2008, pp. 609632.

[15] Polites, G.L. and Karahanna, E. "Shackled to the Status Quo: The Inhibiting Effects of Incumbent System 
Habit , Switching Costs, and Inertia on New System Acceptance.", MIS Quarterly, 36(1), 2012, pp. 21-42.

[16] Seidel, S., Recker, J., and Brocke, J. Vom. "Sensemaking and Sustainable Practicing: Functional Affordances of Information Systems in Green Transformations.”, MIS Quarterly, 37(4), 2013, pp. 12751299.

[17] Strong, D.M., Johnson, S.A., Trudel, J., Volkoff, O., Pelletier, L.R., Bar-on, I., and Garber, L. "A Theory of Organization-EHR Affordance Actualization.” , Journal of the Association for Information Systems, 15(2), 2014, pp. 53-85.

[18] Tversky, A. and Kahneman, D. "Judgment under Uncertainty: Heuristics and Biases.”, Science, 185(4157), 1974, pp. 1124-1131.

[19] Vaast, E., Safadi, H., Lapointe, L., and Negoita, B. "Social media affordances for connective action - an examination of microblogging use during the gulf of mexico oil spill.”, MIS Quarterly, (Forthcoming), 2017.

[20] Volkoff, O. and Strong, D. "Critical Realism and Affordances: Theorizing IT-Associated Organizational Change Processes." , MIS Quarterly, 37(3), 2013, pp. 819834. 